blue schists-are absent because they are above the depth of present erosion. Since that proposition can be neither demonstrated nor refuted his essential thesis amounts to a non-argument. Moreover, the notion of supracrustal erosion of subduction evidence ${ }^{2}$ is difficult to reconcile with the proposed preservation of segments of the ophiolite suite.

He also envisages ${ }^{2}$ a single 1,150 Myr tectonic event, the Petermann Ranges orogeny ${ }^{6}$, during which thrusting, igneous activity and folding, affected basement and cover south of the Amadeus Basin. Within this event, he incorporates the generation of the Woodroffe Thrust as well as the Petermann Ranges nappes in the Dean Quartzite. The whole-rock age of 1,150 Myr used by Davidson ${ }^{2}$ to date the orogeny, however, applies only to a granite unconformably underlying the deformed Dean Quartzite ${ }^{4,6}$; and it has not been demonstrated that basement thrusting further south was necessarily synchronous with cover deformation or granite intrusion. The Petermann Ranges orogeny therefore probably occurred about $600 \mathrm{Myr}^{\mathrm{ago}}{ }^{6}$. As we have indicated $^{7}$, available palaeomagnetic data ${ }^{8-10}$ preclude relative movement between blocks during this period.

The Giles Complex is not, as claimed ${ }^{1.2}$, a 'segment of an ophiolite suite'. The complex consists of intrusive sheets that contain relatively high pressure assemblages $^{11}$ suggesting that it was intruded into the lower continental crust ${ }^{11-13}$. The Gosses Pile ${ }^{1,13}$ is a layered, ultramafic intrusive sheet that crops out $50 \mathrm{~km}$ south of the Woodroffe Thrust and consists of 'orthopyroxenite, websterite, and olivineorthopyroxenite arranged in a cyclic sequence such as is found in the ultramafic parts of other layered intrusions'18. In no way can the Giles Complex be construed as segments of a Proterozoic oceanic crust.

As Davidson ${ }^{1}$ himself has previously noted there are no major lithological and structural differences of basement rocks across the Woodroffe Thrust zone.

Geological ${ }^{14}$ and recent palaeomagnetic ${ }^{15}$ work in certain Precambrian regions has indicated that uniform application of plate-subduction models to such terrains is suspect ${ }^{15}$, and we believe that indiscriminant application of such concepts to terrains not fully understood, may serve only to mask the actual tectonic processes.

Bureau of Mineral Resources, Geology and Geophysics, Canberra, Australia

1 Davidson, D., Nature, 245, 21-23 (1973).

2 Davidson, D., Nature, 253, 657 (1975).

Dewey, J. F., and Bird, J. H., J. Geophys. Res., 76, 2625 (1970).

Letron. Petermann Ranges, $1: 250,000$ geological sheet BMR (1972).

aniels, J. L., Explan. Notes, Scott, 1:250,000 geological sheet, WA Geol. Surv., (1972).

orman, D. J., Rep. Bur. Miner. Resour. Geol.

Geophys. Aust., 87, (1966).

Duff, B. A. and Langworthy, A. P., Nature, 249,
8 Luck, G. R., Geophys. J., 23, 475-487 (1972).

Embleton, B. J. J., Earth planet. Sci. Lett., 17, 217

10 Embleton, B. J. J., and Giddings, J. W., Earth planet. Sci.Lett., 22, 335-365(1974).

Nesbitt, R. W. Goode, A. D. T., Moore, A. C. and Hopwood, T. P., Geol. Soc. of S. Afr., Spec. Publ., 1, (1970).

12 Nesbitt, R. W., Bull. Volcun., 29, 271-281 (1966)

13 Moore, A. C., Geol. Soc, Aust., i8, 69-80 (1971)

Clifford, T. N., in African Magmat ism and Tectonic (edit. by Clifford, T. N., and Gass, I. C.) (Oliver and Boyd, Edinburgh, 1969).

15 Piper, J. D. A., Briden, J. C., and Lomax, K., Nature, 245. 244-248 (1973)

\section{Lunar magnetic anomalies and the Cayley Formation}

MaGnetic anomalies may or may not relate to geological units. Strangway et al. ${ }^{1}$ incorporated geological data in attempting to equate surface anomalies at the Apollo 16 site with those recorded from orbiting Apollo subsatellites, and then correlated the northern plains in the crater Van de Graaff with the Cayley Formation. This correlation is incorrect for three reasons.

First, planar fill in the north end of Van de Graaff is low-albedo mare material with mare ridges, not Cayleylike plains (Fig. 1). Also, the magnetic anomaly near Van de Graaff lies between craters Aitken and Van de Graaff ${ }^{2}$, so that the anomaly could just as easily be ascribed to the acknowledged maria ${ }^{3,4}$ in Aitken. Finally, Strangway et al. ${ }^{\prime}$ cited similar crater densities for the Van de Graaff mare and the Cayley Formation at Descartes, thus implying similar ages. Apollo mapping camera photographs show, however, that the maria in Aitken and Van de Graaff (NASA photographs AS17-1385 and AS15-0076) have similar primary crater densities (Fig. 1) whereas the Cayley plains seem to have significantly more $0.5-1.0 \mathrm{~km}$ craters (NASA photograph AS16-0162) and are therefore older.

Orbital magnetic data do not substantiate the correlation of Cayley-like plains with any particular magnetic signaturc. The other significant magnetic anomalies on the centre far side are not near or over large areas of light plains but instead occur over a wide varicty of terrain ${ }^{2}$; there is no significant anomaly over Cayley Formation plains on the near side of the Moon. If flows of hot breccia from basins were the main cause of lunar magnetic anomalies ${ }^{1}$, then the basin Hertzsprung should show a large anomaly because it is extensively filled with Orientale ejecta. Early reduction of Apollo 15 data $^{2}$ showed a weak anomaly, but this vanished after Apollo 15 and 16 data were integrated (L. R. Sharp and P. J. Coleman, unpublished data).

The outstanding magnetic anomaly between Aitken and Van de Graaff (Fig. 1) correlates with no unique geological feature. The same type of geology occurs elsewhere without magnetic signatures. Therefore, the best explanation for the anomaly remains a subsurface source 2 .

Prepared under a NASA contract.

Desiree E. Stuart-Ai.exander

US Geological Survey,

Menlo Park, California 94025

\footnotetext{
I Strangway, D. W.. Gose, W. A., Pearce, G. W., and McConnell, R. K., Nature, 246. 112-115 (1973).

Sharp, L. R., Coleman, P. J., Jr, Lichlenstein, B. R. Russell, C. T., and Schubert, G., The Moon, 7, 322-341 (1973)

3 Bryan, W. D., and Adams, M. L., Apollo 17 Preliminary Science Report. 32.13-32.14 (NASA

El-Baz, Farouk, Apollo I7 Preliminary Science Report, 32.8-32.12 (NASA-SP-330, 1973).
}

Fig. $1 a$, NASA photograph of the Aitken-Van de Graaff area, showing the low-albedo maria in these two craters and in Marc Ingenii (Orbiter II, moderate 33); b. sketch map shows approximate centre of the magnetic anomaly (X). -, Contacts; - - - crater rim crests; lined pattern, post-mare crater ejecta; " $v$ ' pattern, mare rocks.
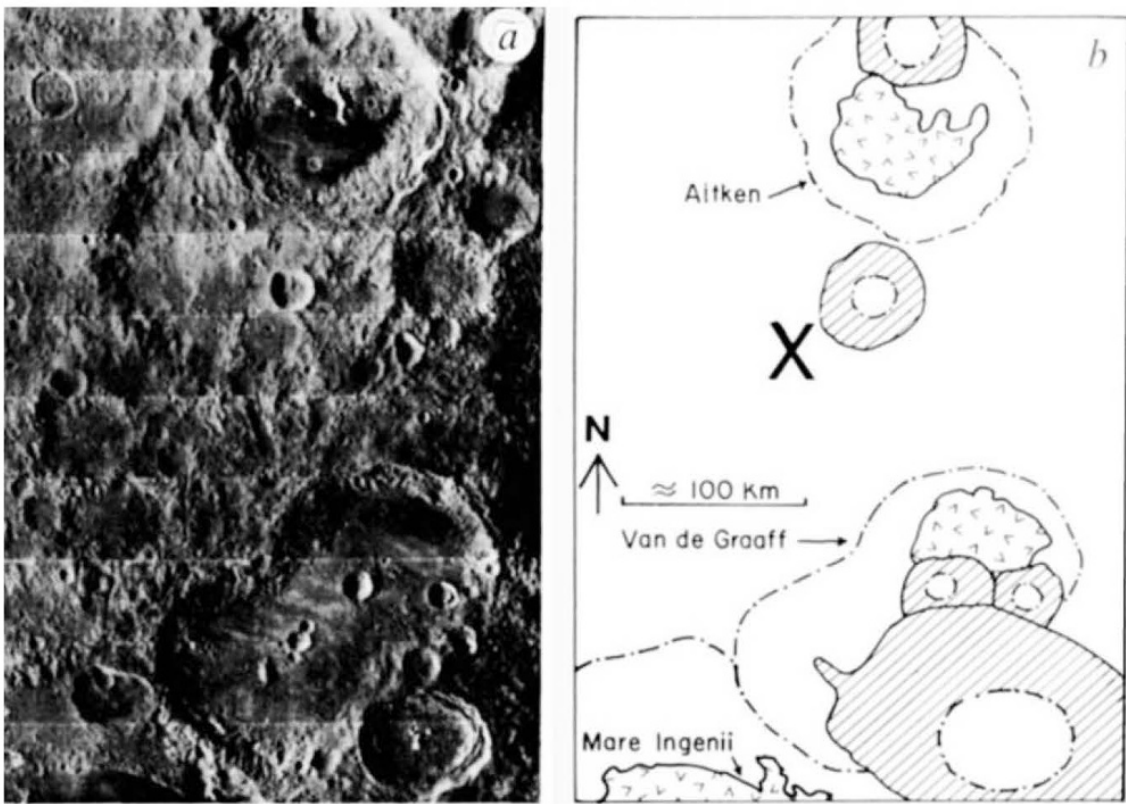